Research Paper

\title{
Cognitive and Emotional Factors Affecting Avoidable Decision-Making Delay in Acute Myocardial Infarction Male Adults
}

\author{
Giulio Vidotto ${ }^{\bowtie}$, Giorgio Bertolotti², AnnaMaria Zotti², Stefano Marchi³, Luigi Tavazzi ${ }^{4}$ \\ 1. Department of General Psychology, University of Padua, Italy; \\ 2. Salvatore Maugeri Foundation, Clinica del Lavoro e della Riabilitazione, IRCCS, Psychology Unit, Medical Centre of Tradate, (VA), Italy; \\ 3. MOSES Centre , 24047 Treviglio, (BG), Italy; \\ 4. GVM Care and Research C/o Villa Maria Cecilia Hospital, 48010 Cotignola, Italy.
}

$\triangle$ Corresponding author: Giulio Vidotto, Department of General Psychology, University of Padua, Via Venezia 8, 35131 Padova, Italy. E-mail: giulio.vidotto@unipd.it Tel: +39 (0) 49.827.6683; fax +39 (0)49.827.6600.

(C) Ivyspring International Publisher. This is an open-access article distributed under the terms of the Creative Commons License (http://creativecommons.org/ licenses/by-nc-nd/3.0/). Reproduction is permitted for personal, noncommercial use, provided that the article is in whole, unmodified, and properly cited.

Received: 2013.01.03; Accepted: 2013.05.05; Published: 2013.07.10

\begin{abstract}
Background: To study the potentially avoidable decision-making delay in acute myocardial infarction (AMI) adults male with different psychological characteristics a nationwide multicentre study was conducted in Italy by the 118 Coronary Care Units (CCUs).

Method: $929 \mathrm{AMI}$ patients consecutively presented to the $\mathrm{CCU}$ in a conscious condition less than two hours, 2-6 hours, 6-12 hours, and more than 12 hours after symptom onset and completing the Disease Distress Questionnaire (DDQ) were enrolled in a multicentre case-control study. The DDQ collects information regarding the decision time to seek help, and includes a set of items assessing psychological factors and pain-related symptoms. The relationship between the perceived threat and the delay due to decision-making was evaluated by means of a multivariate model using LISREL 8 structural equation modelling.

Results: The delay significantly correlated with perceived threat, which was mainly related to somatic awareness. It was only slightly related to pain and was not associated with any of the other variables. Perceived threat was also related to psychological upset, fear and health worries, the first of which was considerably influenced by emotional instability.

Conclusion: Somatic awareness is the main dimension affecting perceived threat, but subjective pain intensity affects the delay both directly and indirectly. The core of the model is the relationship between perceived threat and the delay due to decision-making. The importance of subjective pain intensity is well documented, but it is still not clear how subjective and objective pain interact.
\end{abstract}

Key words: acute myocardial infarction, decision-making, avoidable delay, pain, threat.

\section{Introduction}

The effectiveness of therapy for acute myocardial infarction (AMI) is strictly related to the speed of access to emergency medical care, multiple studies have shown that patients who present within 12 hours of the onset of symptoms benefit the most from reperfusion strategies ${ }^{1,2,3}$. The median delay is different when comparing countries, race and social factors ${ }^{3,4}$ and approximately $50 \%$ of AMI patients arrive too late to benefit fully from thrombolytic or revascularization therapy.5,6

Importantly, in spite of the major advances in efficacy of medical and interventional treatment of 
AMI made in the last years, strictly related to the precocity of the intervention in a USA population ${ }^{7}$ found that duration of pre-hospital delay has remained essential unvaried in the last 20 years.

Despite the many studies that have already been carried out, reasons responsible for the delays and the possibility of reducing the time to hospital arrival are still matter of debate. ${ }^{8,9,10}$ Total delay time is the interval from the onset of symptoms to the initiation of definitive therapy and this time can be divided into three phases: the time of patient/bystander recognition (decision-time), which includes the time between the onset of the symptoms and the decision to seek medical care and the consequent action taken by the patients and those around them (if any); the pre-hospital time from beginning the journey to arriving at the hospital; and the period between hospital arrival and the administration of specific treatment. ${ }^{11}$

The longest phase of delay continues to be the time from symptom recognition to the decision to seek care: the patient/bystander recognition and action phase account for about $80 \%$ of the total delay. The patient/bystander decision-making time involves a complex framework of interrelated variables, most of which have cognitive and emotional aspects; gender could be a bias when male and female data are considered together. ${ }^{12,13}$

Published studies have shown that advanced age, female sex, a low socio-economic status, a history of angina or diabetes, the presence of a family member, self-treatment, the failure to perceive or recognize symptoms as cardiac in origin, evening and early morning hours, and a low level of somatic or emotional state probably increase the delay.,3,6,14-17 Furthermore, mismatches between symptom expectations and experience, and also the interpretation of typical and atypical symptoms are very importan. 9,18 Patients with recurrent AMI showed that a motive for a delay of more than one hour was in all cases a belief that the symptoms would wean or were not serious and acted only when the pain or breathlessness became intolerable. ${ }^{19}$

Furthermore patients who believed that they were having a heart attack sought help quicker than those who did not, and those who waited over 4 hours prior to seeking medical help had significantly lower scores on neuroticism, and higher scores on denial and health locus of control (chance). Confirmatory multiple regression analysis using an alternative estimate of delay in seeking help confirmed that the factor labelled "chance", as measured by multidimensional health locus of control scale, was the best predictor of delayed attendance. ${ }^{20}$ Perry and co-workers showed that beside situations such as having a family member present, patient delay was associated with symptom experience and expectation. ${ }^{21}$

Moreover depression, high family stress, high work stress and major life events had no statistically significant impact on patient delay or total pre-hospital delay. ${ }^{22}$

In spite of some results presented in the literature in a previous Italian study some "somatic" (such as symptom localization, previous experience-AMI) or "psychic" variables (such as the health locus of control), or socio-demographic status (i.e. living with others; single) were not predictive in the model of decision-making delay. ${ }^{23,} 24$ Recently Goldberg et al. showed that median delay times in Europe are longer than in USA and Australia but shorter than in Argentina and $\mathrm{Brazil}^{3}$ and results from a randomized trial found that the education about acute coronary syndrome symptoms and actions required and counselling intervention did not lead to reduced pre-hospital delay or increased ambulance use. ${ }^{25}$

It is well known that pain is a multidimensional experience produced by multiple influences. Vidotto and Bonfiglietti ${ }^{23}$ found that more pain increased and more subjects search for help, vice versa when the subject perceived pain on and off the decision time increased significantly; socio-demographics (ages, gender, education, marital status, household structure) and some clinical factors (angor, syncope, dyspnea) did not affect the delay.

Starting from the database used for a previous report ${ }^{23}$ a new analyses has been done on the potentially avoidable decision-making delay in AMI male patients with different psychological characteristics. This in order to investigate whether: 1) somatic awareness influences perceived threat and this in turn is related to delay in hospital presentation, and 2) the intensity of subjective pain is directly or indirectly affecting the delay.

\section{METHODS}

In the study of the Gruppo Italiano per lo Studio della Streptochinasi nell'Infarto Miocardico, patients with confirmed AMI who consecutively presented to the Coronary Care Unit (CCU) less than two hours, 2-6 hours, 6-12 hours, and more than 12 hours after symptom onset were enrolled. ${ }^{26}$

\section{Subjects}

This study was part of a wider one conducted in Italy by 118 of the CCUs participating in the GISSI network. We considered only the 929 male subjects who were conscious upon their arrival in the hospital and completed all of the parts (none item omitted) of the Disease Distress Questionnaire (DDQ); this sample is $42 \%$ of GISSI-Avoidable Delay subjects. Socio- 
demographic and clinical characteristics were comparable to the general population in terms of the principal parameters ${ }^{26}$; in particular, the percentages of the four admission time categories were very similar (see Table 1). There were some differences in age distribution insofar as only $31 \%$ of our subjects were aged more than 65 years, as against the $45 \%$ in the GISSI population as a whole (see Table 2).

Table I. Distribution of patients in the four admission time categories.

\begin{tabular}{lll}
\hline Admission time & $\begin{array}{l}\text { DDQ* } \\
\text { No. } \%\end{array}$ & $\begin{array}{l}\text { GISSI** } \\
\text { No. } \%\end{array}$ \\
\hline$\leq 2$ hours & $27529.6 \%$ & $60027.1 \%$ \\
$2-6$ hours & $25026.9 \%$ & $60327.3 \%$ \\
$>6-12$ hours & $19521.0 \%$ & $46621.1 \%$ \\
$>12$ hours & $20922.5 \%$ & $54124.5 \%$ \\
\hline
\end{tabular}

* Conscious male AMI patients completing the Distress Disease Questionnaire (DDQ)

**AMI patients in the Avoidable Delay Study ${ }^{26}$

Table 2. Distribution of patients in the three age classes.

\begin{tabular}{lll}
\hline Age & $\begin{array}{l}\text { DDQ }^{*} \\
\text { No. } \%\end{array}$ & $\begin{array}{l}\text { GISSI** } \\
\text { No. } \%\end{array}$ \\
\hline$\leq 55$ & $33836.4 \%$ & $58226.3 \%$ \\
$>55-65$ & $30132.5 \%$ & $63728.8 \%$ \\
$>65$ & $28931.1 \%$ & $99044.8 \%$
\end{tabular}

* Conscious male AMI patients completing the Distress Disease Questionnaire (DDQ)

${ }^{* *}$ AMI patients in the Avoidable Delay Study26

\section{Distress Disease Questionnaire}

The Distress Disease Questionnaire (DDQ) ${ }^{27}$ was administered (self-completed) to all of the enrolled patients by ad hoc trained nurses as soon as the patient could be in stable condition and within a few days of CCU admission.

The patients were asked about their decision-making time (defined as the time between symptom onset and the decision to seek help); the other questions concerned a set of psychological factors and pain-related symptoms ("pain intensity at onset" and "pain intensity at call for medical help") possibly affecting this time, as well as a set of socio-demographic factors. Factor analyses of the psychological items have identified 30 dichotomous items subdivided in five main dimensions describing internal feeling:

Emotional Instability (EI - 7 items) refers to neuroticism construct. Individuals scoring high on this dimension are moody, impatient, and anxious, they are more likely than the average to experience feelings such as anxiety, anger, guilt, and depression mood. They are more likely to interpret ordinary situations as threatening (item example: "I have always considered myself a nervous person"). This dimension has been described in several models of personality including Eysenck's personality ${ }^{28}$.

Psychological Upset (PU- 6 items) refers to the feelings of anxiety state, worry and distress (item example: "I often have the feeling that I can no longer go on").

Fears and health Worries (FW-5 items) consider the general attitude to think through health and illness (item example: "I have always been frightened by diseases");

Perceived Threat (PT- 7 items) refers to the Health Believe Model ${ }^{29}$ and explore opinion and belief on disease and the behavior they encompass to the disease (item example: "I tried not to think about what it could be");

Somatic Awareness (SA) refers to perception, interpretation, and act on information from specific cardiovascular system (item example: "I immediately thought it had something to do with my heart"); with Cronbach alpha in the male sample comprised between 0.7 and $0.8{ }^{27}$ and these value were indicated as satisfactory for comparing groups. ${ }^{28}$

\section{Statistical Analysis}

On the basis of some theoretical assumptions and data considered in a previous preliminary research $^{23,24}$ a structural equation model to explain the delay in decision-making was developed. The variables considered in these analyses were five psychological factor measures, two pain evaluations ("pain intensity at onset" and "pain intensity at call for medical help"), and decision times. The aim of these previous works was to define a parsimonious model to evaluate the effect of a number of potential psychological risk factors on the delay on a sample of only males with IMA arriving conscious at the hospital. It is worth noting that these preliminary results did not suggest a unique model for male and female. ${ }^{24}$

We then performed a confirmatory structural equation analysis based on the correlation matrix of the 929 male subjects comprehending decision-making time, pain intensity and psychological factors - to test all of the main effects, while controlling for emotional instability and pain at symptom onset, was considered. 31

The used fitted indexes were: goodness of fit index (GFI), adjusted goodness of fit index (AGFI), parsimony goodness of fit index (PGFI), and the standard chi-square statistic. ${ }^{32}$ Finally, the measurement model derived from the analyses was used to weight the contribution of the indicators to the constructs in the multiple regression analyses. 


\section{RESULTS}

The estimated standardized path coefficients and overall fit indices for the model, based on the correlation matrix presented in table 3, are shown in Figure 1; the results indicate that the model fits the data adequately. It can also be seen that the delay significantly relates to the perceived threat (which was mainly linked to somatic awareness), but only slightly to the pain and that it is not associated with any of the other variables. Perceived threat also relates to psychological upset, fear and health worries. Finally, emotional instability is closely related to psychological upset, and slightly related to fear and health worries.
Table 3. Correlations among psychological indicators, pain intensity (PO; PH), and delay (DT).

\begin{tabular}{|l|l|l|l|l|l|l|l|l|}
\hline & $P T$ & $S A$ & $E I$ & $P U$ & $F W$ & $D T$ & $P O$ & $P H$ \\
\hline$P T$ & 1.0000 & & & & & & & \\
\hline$S A$ & 0.3729 & 1.0000 & & & & & & \\
\hline$E I$ & -0.0012 & 0.1063 & 1.0000 & & & & & \\
\hline$P U$ & -0.1026 & 0.0483 & 0.4507 & 1.0000 & & & & \\
\hline$F W$ & 0.1326 & 0.0393 & 0.2308 & 0.2376 & 1.0000 & & & \\
\hline$D T$ & -0.2776 & -0.1418 & -0.0191 & 0.0123 & -0.0622 & 1.0000 & & \\
\hline PO & 0.1127 & 0.0782 & 0.0386 & 0.0297 & 0.0066 & -0.1031 & 1.0000 & \\
\hline PH & 0.1068 & 0.1214 & 0.0337 & 0.0123 & 0.0003 & -0.1113 & 0.7045 & 1.0000 \\
\hline
\end{tabular}

Legend: $\mathrm{PT}=$ perceived threat; $\mathrm{SA}=$ somatic awareness; $\mathrm{EI}=$ emotional instability (neuroticism); $\mathrm{PU}=$ psychological upset; $\mathrm{FW}=$ fear and health worries; $\mathrm{DT}=$ decision-making time or avoidable delay; $\mathrm{PO}=$ pain intensity at symptom onset; $\mathrm{PH}=$ pain intensity at time of calling for help.

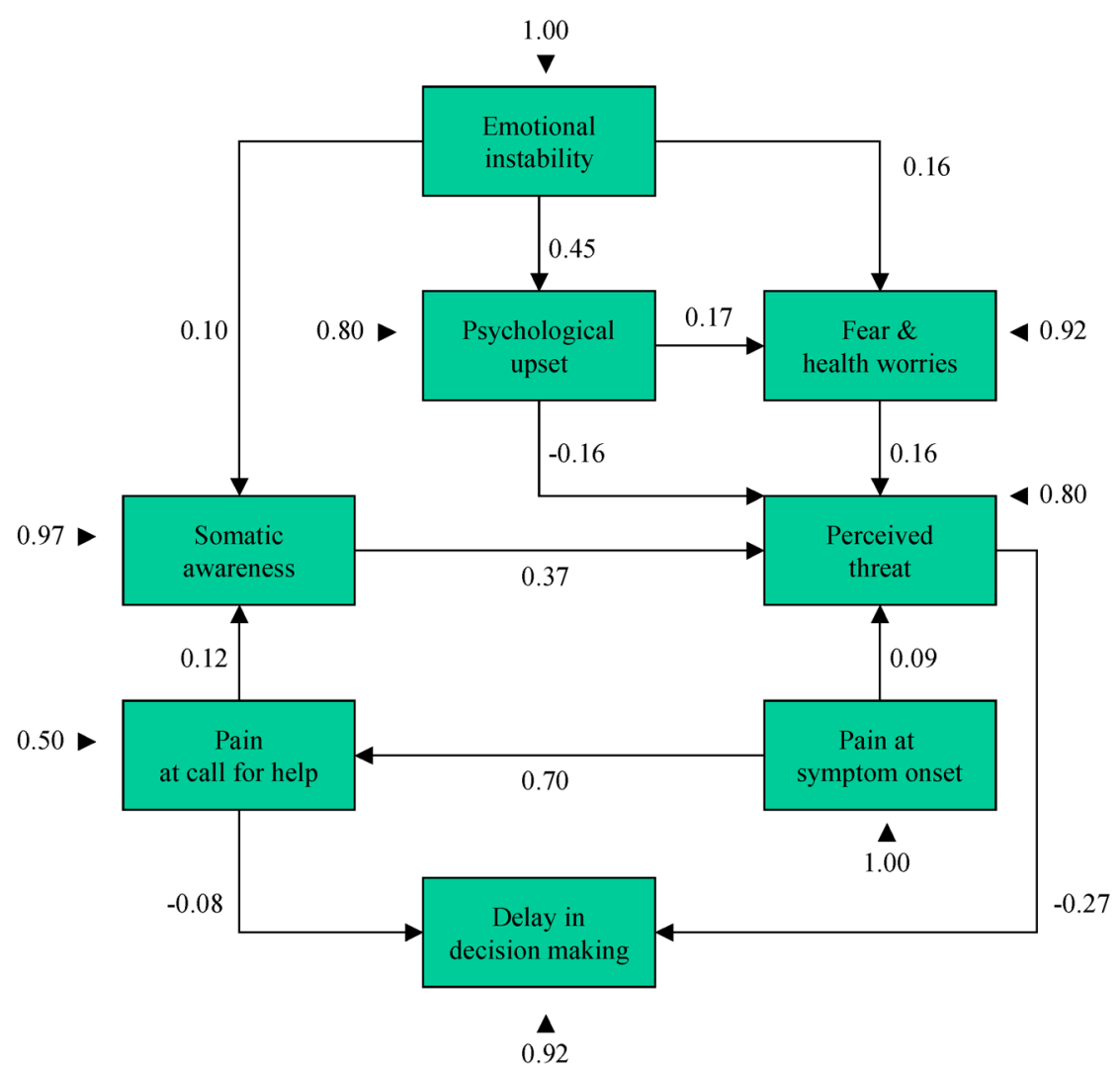

Figure I. Model predicting decision-making delay. The error (close to black triangle) and coefficient values from the regression matrix are shown in the figure. Minimum Fit Function Chi-Square $X^{2}{ }_{15}=3.5499(p=0.999)$; Goodness of Fit Index GFI = 0.999; Adjusted Goodness of Fit Index AGFI = 0.998; Parsimony Goodness of Fit Index PGFI = 0.4I6.

To better account for the delay due to Decision-making Time (DT), we report linear equations where letters indicate the standardized values of the variables (see legend of Table 3):

$$
\mathrm{DT}=-0.27 \mathrm{PT}-0.08 \mathrm{PH} \text {, }
$$

where $\mathrm{PT}=$ Perceived threat; $\mathrm{PH}=$ Pain intensity at time of calling for Help.
PT can therefore be estimated using the following equation:

$$
\mathrm{PT}=0.37 \mathrm{SA}-0.16 \mathrm{PU}+0.16 \mathrm{FW}+0.09 \mathrm{PO},
$$

where SA = somatic awareness; $\mathrm{PU}=$ psychological upset; FW = fear and health worries, and $\mathrm{PO}=$ Pain intensity at symptom Onset.

Pain intensity at time of calling for Help (PH), 
Somatic Awareness (SA), Psychological Upset (PU), and Fear and health Worries (FW) have the following four estimation functions:

$$
\begin{gathered}
\mathrm{PH}=0.70 \mathrm{PO}, \\
\mathrm{SA}=0.10 \mathrm{EI}+0.12 \mathrm{PH}, \\
\mathrm{PU}=0.45 \mathrm{EI}, \\
\mathrm{FW}=0.16 \mathrm{EI}+0.17 \mathrm{PU} .
\end{gathered}
$$

where EI = emotional instability (neuroticism).

The squared multiple correlations for the six structural equations are: $\mathrm{r}^{2} \mathrm{DT}=0.084, \mathrm{r}^{2} \mathrm{PT}=0.184$, $\mathrm{r}^{2}{ }_{\mathrm{PH}}=0.496, \mathrm{r}^{2} \mathrm{SA}=0.025, \mathrm{r}^{2} \mathrm{PU}=0.203, \mathrm{r}^{2} \mathrm{FW}=0.076$.

\section{DISCUSSION}

The model has a good fit, and is coherent with our initial hypothesis and other published results: some psychological dimensions and the subjective evaluation of pain intensity may be good predictors of delay and, possibly, they interact mutually.

Generally speaking, given the very complex interactions of the psychological characteristics describing internal feeling state/traits (i.e. emotional instability, psychological upset, fears and health worries), and clinical symptoms related to pre-hospital delay (decision-time), we concentrated on how patients make sense of their symptoms and decide whether they need urgent medical help.

The core of the model lies in the relationship between perceived threat and the delay due to decision-making. Somatic awareness is the main dimension influencing perceived threat, and subjective pain intensity (decision to call for help) is the other important variable that affects the expectancy of the delay both directly and indirectly. The effect of the psychological factor measures on delay is controversial, but sensitivity expressed by emotional instability (i.e. higher neuroticism) has a slight influence on somatic awareness, psychological upset, and fear and health worries, the last two of which only slightly influence the perceived threat. It is well known that individuals who score high in neuroticism are more reactive to stressful situations. ${ }^{33-35}$

All of these relationships underline the complexity of the studied phenomenon, but also emphasize the fact that the main agent reducing delay is the perceived threat, whose role and relationship with somatic awareness are the main points to consider when trying preventing avoidable delay. The other major variable is pain intensity: the importance of subjective pain intensity is well documented, but it is still not clear how subjective pain and symptoms interact. We know that an AMI can induce pain in different localizations and with different degrees of intensity. ${ }^{36}$ Perry et al. has pointed out that "...the real- ity for many patients ... [is] that the onset of symptoms of MI [are] less dramatic than expected" and so the subjective evaluation of pain intensity may lead to misjudge the physiological alarm and its seriousness. ${ }^{21}$

Undoubtedly physiological and psychological interdependence in judging underlying symptom perception have an influence on angina that is independent and additive to the severity of underlying ischemia. ${ }^{36,37}$

The GISSI study ${ }^{26}$ emphasizes the fact that, in subjects treated less than two hours after the onset of symptoms, only $23 \%$ of the time is due to decision making; however, this increases to $35 \%$ if the total delay is $2-6$ hours, to $71 \%$ if it is $6-12$ hours, and to $80 \%$ if it is more than 12 hours. For this reason, we would like to underline the potential importance of this first model explaining the time taken by patients to respond to the symptoms and signs of an AMI even though the size of explained variance is small.

Pain is a multidimensional phenomenon composed of sensory, emotional, cognitive, and social-situational components that interact to produce the total pain experience and a subjective adaptive behaviour as consequence. ${ }^{38}$ This implies that "knowledge" of symptoms and of the exact consequent appropriate behaviour to take will not shorten, on its own, decision time. Pain perceived intensity and, even if to a lesser extent, emotional instability seem play an active function on increasing somatic awareness; consequently the subject is watchful and prompt to meet danger or emergency, or being quick to perceive threat of danger and act. According with Schachter and Singer, an emotional state is the result of an interaction between two components: a) physiological arousal and b) an interpretation of the arousing situation. ${ }^{39}$ Arousal would determine only the intensity of emotion while the interpretation determines which emotion, if any, will be experienced; and as stated by Kenyon et al "Variations in sensitivity to bodily sensations and emotions appear to play an important role in treatment seeking and thus potentially in treatment outcome for AMI patients" (p.1969). ${ }^{15}$ In other words, difficulties to reduce delay are still substantial because it is complex for patients to be aware of and to evaluate symptoms. ${ }^{14,40}$ Several demographic and medical history factors were associated with extent of pre-hospital delay in patients with acute coronary disease, including advanced age, selected co-morbidities, social, cognitive, and emotional factors and in the different geographic locations. ${ }^{3,6,41}$ In a Polish cross sectional study the authors suggest to improve knowledge and attitudes related to the delay phase, however the study did not include psychological factor which modification or its man- 
agement should be not easy in daily practice. ${ }^{42}$

A limitation of the study could be found in the inability to generalize findings to population of women.

Our results are consistent with our initial hypothesis that psychological factors play a role in the delay, but this study adds to previous knowledge some interesting new evidence of the relationship between decision-making time and both somatic awareness and perceived threat sustaining the "common-sense representation of illness" model 43,44 and others similar results recently found. 45

We trust that results found in this study demonstrate the extreme difficulty to help the individual in decision, probably because its hesitation it will depend on knowledge and awareness of a merge of psychophysical cues.

Recently Michie et $\mathrm{al}^{46}$ published a paper oriented to define a new method useful for designing behavioural intervention. This model involves nineteen frameworks in three-level circles from "policy categories" to "intervention functions" and a molar of "Sources of behaviour". The 'behaviour system' is in the centre and involves three essential conditions: capability, opportunity, and motivation ('COM-B system') and our results could partly cover this core of variables involved in decision-delay for acting behaviour.

\section{Competing Interests}

The authors have declared that no competing interest exists.

\section{References}

1. Gruppo Italiano per lo Studio della Streptochinasi nell'Infarto miocardico (GISSI). Effectiveness of intravenous thrombolytic treatment in acute myocardial infarction. Lancet 1986;1:397-402.

2. Fibrinolytic Therapy Trialists' (FTT) Collaborative Group. Indication for fibrinolytic therapy in suspected acute myocardial infarction: collaborative overview of early mortality and major morbidity results from all randomised trials of more than 1000 patients. Lancet 1994;343:311-22.

3. Goldberg RJ, Spencer FA, Fox KA, et al. Pre hospital delay in patients with acute coronary syndromes (from the Global Registry of Acute Coronary Events [GRACE]). Am I Cardiol. 2009;103:598-603.

4. Cooper RS, Simmons B, Castagner A, Prasad R, Franklin C, Ferlinz J. Survival rates and prehospital delay during myocardial infarction among black persons. Am J Cardiol 1986;57: 208-11.

5. Tavazzi L. Clinical epidemiology of acute myocardial infarction. Am Heart J 1999;138 (Suppl 2): S48- S54.

6. Moser DK, Kimble LP, Alberts MJ, et al. Reducing delay in seeking treatment by patients with acute coronary syndrome and stroke: a scientific statement from the American Heart Association Council on cardiovascular nursing and stroke council. Circulation. 2006;114:168-82.

7. Nguyen HL, Gore JM, Saczynski JS, et al. Age and sex differences and 20-year trends (1986 to 2005) in prehospital delay in patients hospitalized with acute myocardial infarction. Circ Cardiovasc Qual Outcomes 2010;3:590-8.

8. Khraim FM, Scherer YK, Dorn JM, Carey MG. Predictors of decision delay to seeking health care among Jordanians with acute myocardial infarction. J Nurs Scholarsh 2009;4:260-7.

9. Perkins-Porras L, Whitehead DL, Strike PC, Steptoe A. Causal beliefs, cardiac denial and pre-hospital delays following the onset of acute coronary syndromes. J Behav Med 2008;31:498-505.
10. Perkins-Porras L, Whitehead DL, Strike PC, Steptoe A. Pre-hospital delay in patients with acute coronary syndrome: factors associated with patient decision time and home-to-hospital delay. Eur J Cardiovasc Nurs 2009;8:26-33.

11. Alonzo AA. The impact of the family and lay others on care seeking during life-threatening episodes of suspected coronary artery disease. Soc Sci Med 1986;22: 1297-311.

12. Gesensway D. Reasons for sex-specific and gender-specific study of health topics. Ann Intern Med 2001;135: 935-8.

13. Vermeer F. Thrombolytic therapy in patients of female gender. Thromb Res 2001; 103 Suppl 1:S101-4.

14. Dracup K, Moser KM, Eisenberg M, Meischke H, Alonzo AA, Braslow A. Causes of delay in seeking treatment for heart attack symptoms. Soc Sci Med 1995; 40:379-92.

15. Kenyon LW, Ketterer MW, Gheorghiade M, Goldstein S. Psychological factors related to prehospital delay during acute myocardial infarction. Circulation 1991;85:2193-5.

16. Berton G, Cordiano R, Palmieri R, Guarnieri G, Stefani M, Palatini P. Clinical features associated with pre-hospital time delay in acute myocardial infarction. Ital Heart J 2001;2:766-71.

17. Turris SA. Women's decisions to seek treatment for the symptoms of potential cardiac illness. J Nurs Scholarsh 2009;4:5-12.

18. Horne R, James D, Petrie K, Weinman J, Vincent R. Patients' interpreting of symptom as a cause of delay in reaching hospital during acute myocardial infarction. Heart 2000;83:388-93.

19. Pattenden J, Watt I, Lewin RJ, Stanford N. Decision making processes in people with symptoms of acute myocardial infarction: qualitative study. BMJ 2002; 324: 1006-9.

20. O'Carroll RE, Smith KB, Grubb NR, Fox KA, Masterton G. Psychological factors associated with delay in attending hospital following a myocardial infarction. J Psychosom Res 2001;51:611-4.

21. Perry K, Petrie KJ, Ellis CJ, Horne R, Moss-Morris R. Symptom expectations and delay in acute myocardial infarction patients. Heart 2001;86:91-3.

22. Løvlien M, Schei B, Hole T. Myocardial infarction: psychosocial aspects, gender differences and impact on pre-hospital delay. J Adv Nurs 2008;63: 148-54.

23. Vidotto G, Bonfiglietti A. Avoidable delay in therapy for acute myocardial infarction; Using structural equation modeling to understand the relationships between psychological factors and patient decision making. In: Boscolo P, Cristante F, Dellantonio A, Soresi S, eds. Aspetti qualitativi a quantitativi nella ricerca psicologica. Padua: Il Poligrafo. 1996.

24. Marchi S. The avoidable delay in the acute myocardial infarction: model of structural equations [dissertation in Italian]. Padua: University of Padua, 1997.

25. Dracup K, McKinley S, Riegel B, et al. A randomized clinical trial to reduce patient prehospital delay to treatment in acute coronary syndrome. Circ Cardiovasc Qual Outcomes 2009;2:524-32.

26. GISSI Avoidable Delay Study Group. Epidemiology of avoidable delay in the care of patients with acute myocardial infarction in Italy. A GISSI-generated study. Arch Intern Med 1995;155:1481-8.

27. Bertolotti G, Bettinardi O, Michielin P, Sanavio E, Vidotto G, Zotti A.M. Disease Distress Questionnaire. Milano: Burke Data, 1990. (In Italian)

28. Eysenck HJ, Eysenck SBG. Manual of the Eysenck Personality Questionnaire. London: Hodder and Stoughton. 1975.

29. Rosenstock IM, Strecher VJ, Becker MH. Social Learning Theory and the Health Belief Model. Health Education \& Behavior 1988; 15 (2): 175-183.

30. Bland JM, Altman DG. Cronbach's alpha. BMJ. 1997;314:572.

31. Jöreskog KG, Sörbom D. Lisrel 8; User's reference guide. Chicago: Scientific Software International Inc. 1996.

32. Bollen KA. Overall fit in covariance structure models: Two types of sample size effects. Psychological Bulletin, 1990;107(2): 256-259.

33. Torki MA. Associations between personality and stress reactions during and after invasion of Kuwait. Psychol Rep 1994;74:667-73.

34. Bolger N, Schilling EA. Personality and the problems of everyday life: the role of neuroticism in exposure and reactivity to daily stressors. J Pers 1991;59:355-86.

35. Robinson MD, Ode S, Wilkowski BM, Amodio DM. Neurotic contentment: A self-regulation view of neuroticism-linked distress. Emotion. 2007;7: 579-91.

36. Malliani A. Pathophysiological mechanisms and the loss of a finalistic purpose. In: Malliani A, ed. Principles of Cardiovascular Neural Regulation in Health and Disease. Boston: Kluwer Academic Publisher; 2000:48-61.

37. Maseri A. Ischemic heart disease. In a rational basis for clinical practice and research. New York: Churchill Livingstone, 1995.

38. Melzack R,Wall P. The Challenge of Pain. Harmondsworth: Penguin, 1982 
39. Schachter S, Singer J. Cognitive, social and physiological determinants of emotional state. Psychological Review 1962;69:379-99.

40. Dracup K, Moser DK. Beyond sociodemographics: factors influencing the decision to seek treatment for symptoms of acute myocardial infarction. Heart Lung 1997;26:253-62.

41. Goldberg RJ, Steg PG, Sadiq I, et al. Extent of, and factors associated with, delay to hospital presentation in patients with acute coronary disease (the GRACE registry). Am J Cardiol 2002;89:791-6.

42. Kopec G, Sobien B, Podolec M, et al. Knowledge of a patient-dependant phase of acute myocardial infarction in Polish adults: the role of physician's advice. Eur J Public Health 2010;23:1-6: doi: 10.1093/eurpub/ckq110.

43. Leventhal H, Diefenbach $M$, Leventhal EA. Illness cognition: Using common sense to understand treatment adherence and affect cognition interactions. Cognitive Therapy and Research, 1992, 16: 143-163

44. Walsh JC, Lynch M, Murphy AW, Daly K. Factors influencing the decision to seek treatment for symptoms of acute myocardial infarction: an evaluation of the Self-Regulatory Model of illness behaviour. J Psychosom Res. 2004 Jan;56(1):67-73.

45. Fox-Wasylyshyn SM, El-Masri M, Artinian NT. Testing a model of delayed care-seeking for acute myocardial infarction. Clin Nurs Res 2010;19:38-54.

46. Michie S, van Stralen MM, West R. The behaviour change wheel: A new method for characterising and designing behaviour change interventions. Implement Sci. 2011 Apr 23;6:42 